\title{
Sustainability of the Public Health Service in Spain: an Approach to Governance
}

Presented at 1st International Online BioMedical Conference

ORIGINAL

\section{Abstract}

The health system sustainability is a key topic in Spain's political debates. What a sustainable heath system should be poses a big concern for citizens and politicians. Foremost for managers and political actors, to ascertain the right way to build a good mid- and large-term financial model of sustainability is critical as well. However, to link exclusively the financial sustainability of the health system with a political objective could be a limited overview. Issues that affect the national health system have an impact on the entire society and its processes and activities result in environmental externalities. The analysis focuses on the triple bottom line: economic, social and environmental; displaying a wider view of the Spanish health models and their future strategies. Likewise, it needs to be understood whether the concept of sustainability goes beyond the economical concerns in the plans of the health authority and their financial budgets, and come to terms with the expectations of citizens and the political speech, considering that the health budgets of Spain and other OECD countries show a weakness point in this regard. This article analyzes the challenges of the health system and its critical points from the perspective of the health authority.
Miguel Á. Moyano-Santiago', Juana M. Rivera-Lirio'

1 Department of Finance and Accounting, University Jaume I, Castellón de la Plana, Spain.

Contact information:

Miguel Á. Moyano-Santiago.

Address: University Jaume I, Avenue Vicent Sos Baynat, n/n. 12071 Castellón de la Plana, Spain.

Tel: +34964387140

Fax: +34964728565

” moyanoma@me.com

Keywords

Equity; Sustainability; Health Policy; Costs.

\section{Introduction}

To formulate an appropriate development pattern for a sustainable society is still a critical issue (SUMI, 2007), to the extent that it requires further development in the understanding of the dynamics and workings of social systems and Complex organizations (Kates et al., 2001). Even the term sustainability takes on different meanings in different contexts, usually being translated with a strong environmental bias or interpreted from a strictly economic perspective; thereby obviating the close and reciprocal relations between the economic, social and en- 
vironmental dimensions of development (KomiYAMA and TAKEUCHI 2006). As highlighted by SumI (2007) we live in a socioeconomic system constructed from a natural system, and to try to develop the social system in order to increase to the fullest economic benefits may have a negative impact on the natural system, and perhaps upon the human system itself, having the potential to cause environmental and health problems.

Health still remains a key issue in the socio-political debate in the beginning of XXI century: three out of the eight Millennium Development Goals (MDGs) of the UN are related to health: reducing child mortality rates, improving maternal health, and combating HIV/AIDS, malaria and other diseases (WHO, 2000). In particular, influenced by the setting of the current crisis, the sustainability of the health system has been at the forefront of the European political agenda. To assess the true dimension of the problem, it is necessary to understand the concept of "health system" as well as the strategies to follow from both public and private approaches in the medium and long terms. The fundamental question that arises is whether the question increasingly raised and heard in economic and health forums: "Is the Health System sustainable?" does not refer actually to whether or not the payment of the health bill from the current model is affordable from a financial perspective (THomson et al., 2009).

As noted by the Report on World Health 2000 (WHO, 2000), "governments must be the governing bodies of national resources, preserving and improving them for the benefit of the population. In health, this ultimately means taking a careful management of the public welfare." Authors such as VeILLARD et al., (2011) indicate that the current economic and financial crisis has highlighted even more, if possible, the importance of well-functioning health systems, as well as the need for government action to improve public health and to encourage efficiency.

Even when considering that the constraints brought upon them by the current financial crisis are crucial in the management of public funds, the sustainability of the system in social and environmental terms should be addressed, as it can be instrumental in increasing financial efficiency, and therefore, in achieving a positive influence in the financial viability, thereby replicating the so-called "virtuous circle" (WADdock and Graves, 1997) in the management of organizations under standards of sustainability. The problems associated with the burden of the National Health System are borne by society as a whole. The environmental dimension might be also compromised, since both the public and private management of financial and material resources used by the system have an impact on the natural environment.

In this context, this paper aims to analyze the vision that the public managers of the Spanish health system have on what a sustainable health system should be, Comparing this view with a concept of sustainability of the health system understood from a broad perspective, i.e., considering both financial and economic issues, including social and environmental dimensions.

The structure of the paper is as follows. After this brief introduction, the next section will address the concept of sustainable health systems, laying the foundation for the planning of research objectives. A third section describes the Spanish healthcare system as a case study. The following section will detail the methodology used and the results obtained. To conclude the main conclusions drawn will be set forth.

\section{The sustainable management of health systems}

Health and sustainable development are closely connected. Health besides Bringing well-being to individuals is a powerful tool for social and economic Development (BRUNDTLAND, 2002).

A healthcare system or health system can be understood as "the set of organizations, institutions and public and private resources intended to impro- 
ve, maintain or restore health. The health system includes personal services and the whole population, as well as activities aimed to influence the policies and actions of other sectors in order to address the economic, social and environmental that are instrumental to health" (WHO Regional Office for Europe, 2008). Therefore, addressing the sustainability of the health system from a strictly financial point of view, regardless of their interrelationships with social and environmental aspects, involves reducing the scope of the term sustainability associated with health systems.

What do we call a sustainable health system is controversial in debates about health policy, and it is therefore a major concern both in public perception and in the political class to find a way to achieve financial sustainability in the medium and long term (KICKBUSCH, 2009). On the other hand, we should not overlook that would there be a collapse of an affordable national health system; the burden would be simultaneously supported by citizens and businesses (WERBANCH, 2009), i.e., by the whole society. The environmental dimension may be also compromised because the science of sustainability seeks to respond to the substantial, but limited understanding of the interactions between nature and society, and the impact of these interactions in humans (Kates et al., 2001). It therefore seems necessary to attest the importance and the integration of the triple bottom line: economic, social and environmental health policy, and to question at the same time, the importance of the economic factor as the only approach able to set a difference.

The lack of acknowledgement of the importance of the three dimensions of sustainability may be due to a limited understanding of the concept ( $E L$ ANSARI and StIBBE, 2009), and therefore of assimilation that in the multiple bottom line each environmental issues, economic, social and cultural right is important. In fact, as pointed by Jameton and Mcguire (2002), the problem to solve in the sustainability of the health system is the balance bet- ween the different aspects of it. To define the term sustainability, Jameton and Mcguire (2002) cite Elkington (1998) stating that "the sustainability of the health system is characterized by a balance between considerations in patient care, environmental costs of the activity and accessibility to system, and an adequate supply of services (...)", which is a very similar approach to the well established triple bottom line." Along the same lines, Pecurul and Peray (2010) argue that it has been shown that partial solutions for each area of sustainability lead to uncoordinated actions that do not take into account the relationship between economic, social, and environmental aspects.

There is no doubt that the economic concerns and the finances of the health system financing are on the table for every public manager, but perhaps not so much, a degree of candid openness to the other two dimensions. Health plans could be an excellent tool to raise strategic awareness and to measure intentions regarding the consequence given to the different dimensions of sustainability in the Brundtland sense.

\section{Social dimension}

Health and diseases are the result of social action, of the way people lead their lives, and of the context in which they do it (Potvin et al., 2005). Given this fact, one might argue that the formulation of health programs and plans should consider integrating social theories, or the most significant contributions from structuralism and rationality in the decision making of individuals, with the intention of enhancing the preparation of such strategic plans. There are three theoretical lines suggested by the authors may reflect the constraints that nowadays are a result of social influence. First, the consequences of human activity that are inherent in any complex system; second, a critical approach to the structural bureaucratic model; and third, a epistemological reflection that may overcome the dilemma objectivity-subjectivity. This healthification of social issues, say the 
same authors, is an important way to incorporate the most advanced social theories when formulating health programs.

The institutional awareness about the relevance of social decisive factors on public health is observable in a long history of events that happened in the recent decades. The Alma Ata Declaration of 1978, pointed to the obligation of governments to take care of the population by appropriate social measures. In 1986, it was published the Ottawa Charter as a result of the global conference on health promotion, reflecting that Complex societies cannot separate the health from other goals, and that the ties between the individual and the environment where he lives require a socio-ecological approach to health (OTTAWA, 1986). In the same series of lectures held in 2005 in Bangkok, it was established as the basis for control of the determinants of health an integrated approach by government and international agencies, and more precisely, a commitment to Work with civil society and the private sector (BANGKOK, 2005). On May 22 ${ }^{\text {nd }}, 2009$, took place the 62th World Health Assembly, whose title: "Reducing Health Inequities through Action on the Social Determinants of Health", clearly indicates the importance of this dimension. The following UN resolution, WHA62.14, urged literally states to "take into account health equity in all national policies on social determinants" and along the same line, in that resolution, the Commission requests the Director General "to make the social determinants of health a guiding principle for the application of measures, including objective indicators for monitoring the social determinants of health... and in particular, in public health programs" (WHO, 2009). The Rio Political Declaration of 2011, cited in its second point: "We recognize that governments are responsible for the health of its population, and can only fulfil this obligation by adopting appropriate social and health measures " (WHO, 2011).

Furthermore, as highlighted by Jochelson (2006), there is evidence of the role that the state can play as a provider of information for the informed decision making of citizens regarding their health. According to the author, the example of the announcements relating to the consequences of alcohol and tobacco show a clear decline in the use by citizens and their positive impact on arising lower morbidity and mortality; these measures along with the tax burden try to influence consumers when making decisions. In 2004, the Health Department of the British Government, published "Choosing Health, Making Healthy Choices Easier" (DoHuk, 2004). It regards an overview of the responsibilities of the government of that country in motivating lifestyle changes in the population, to strengthen personal responsibility in health decisions; it was a firm commitment to bring closer the role of the state as a protector to the field of influence of personal decisions. The fact that the state can play a guiding role in personal behaviour, however, as some Spanish authors point out, also has its detractors, but it seems that we as humans, find easier recognize patterns than thinking through sequences and logical combinations as indicated by Repullo (2009).

A key question seems to be the understanding of sustainable model from a perspective that integrates the factors that affect the health of the population (FIONA et al. 2006). As health and wellbeing go hand in hand with economic prosperity, and both may contribute in turn to environmental improvement, it would take a clean break in the investigation into health planning, far from traditional regards based on the provision of services, to carry out a holistic, new form of action, since if new initiatives aspire to seek health in every policy, it would be necessary to introduce elements to assess the impact on health of the different human activities (Benedict and Oñorbe, 2010).

There is therefore, evidence that social aspects could pose an efficient support on Issues such as the adherence to treatment, the motivation of the chronically ill, or family involvement that should be further emphasized and supported by health 
programs in order to succeed and attain a more comprehensive view of the whole system (BAXTER, 2010).

\section{Environmental dimension}

The climate has a great influence in the different fields of life; extreme temperatures, floods, heat waves and other atmospheric phenomena affect biodiversity and have consequences on the health of people (HAYNES et al. 2006). One of the most recent examples was the heat wave of 2003 in Western Europe, where the number of deaths as a result of overheating during the summer was according to these authors, of 2,000 victims in England and Wales and of 14,800 in France. Climate change is just one of the many ways that health authorities may consider regarding both environment and health, and it seems important to determine which aspects would be required to regard in planning to reduce the relative weight of the impact of climate and environment on the results of public health (EBI and BURTON. 2008); what environmental determinants are relevant to health and what results may occur, how they are measured, how to reduce the impact, and to adapt the structures, etc.? But it is not only on the death rate where the climate or the environment may have an impact; an increased morbidity also produces greater disability, and has an impact on the economies of the countries. WHO points to the importance of the global burden of disease considering variable life years free from disability (Seuc and Dominguez. 2002). As it is known, the cohorts of population that are socioeconomically disadvantaged suffer more severely the consequences of inadequate housing and their thermal, hygienic and insalubrious effects. Both the environment and housing are key issues in the health and welfare of people and have a significant impact in areas such as mental health (GUITE et al. 2006). The perception of safety in the streets or in a neighbourhood, the cleanliness, the crime rates and social participation play a significant role. The pollution factor, brought by noise or the emission of chemicals, has a direct effect on the socioeconomic determinants of health and health (PECURUL and Peray, 2010).

Other more unusual actions related to the environment are also possible and it could be convenient to explore the feasibility of their implementation, like the use of waste from healthcare facilities to produce positive externalities. An example might be the recycle of biological waste into fertilizer as described in HeInONEn-TANSKI et al., (2010).

\section{Economic and financial dimension}

In an environment of economic crisis, the financial and economic dimensions take on a predominant role in the political that concerns sustainability of the health system. The pressures of an aging population and the increasing prevalence of chronic diseases result in formidable strains on budgets. According to authors such as Gérvas and Meneu (2010), there are in developed societies, two cultures that are often obvious, in relation to public health issues. On the one hand, one that relates to an excessive use of health resources tries to seek the aim of permanent health. On the other hand, the pressures of an aging population and the increasing prevalence of chronic diseases deliver utmost tension on budgets.

As mentioned by Martin and Lopez del Amo (2011), the basic strategies in the public health sector to ensure economic sustainability are basically finalist, such as increasing taxation and improving the efficiency in the provision of services.

Finalist taxation is one of the most recurrent key aspects in the current forums on sustainability of the health system. The assignment of the funds provided by citizens to ensure public health, among other aims that are of public interest, have result in tensions as more voices are raised calling out for the need to provide specific tax allocations to avoid funds transfers to other areas of public expenditure. 


\section{The role of public managers in health systems}

The goals of sustainability of the health system, especially the financial ones, are parallel to certain ideological paradigms in managers such as equity, which are at the same time, unresolved objectives in the public health systems of the European environment as noted by Potvin et al., (2010). To improve health inequity caused by the differences in socioeconomic upbringing is also a matter of political leadership, particularly from the local authorities, which are closer to disadvantaged communities (Rae, 2006).

The health of populations depends, among other factors, of the ability to have access to adequate medical services. The sustainability of the health system faces the need for equity and access from the whole of society smoothing over regional and class differences in order to contribute to a real social and economic development, as noted in the 2002 Brundtland's report "Health and Sustainable Development". This aspect is well known and well assimilated by the political class that emphasizes accessibility as a key element along with the cohesion and universality of the system. If the ultimate goal, as stated by Отео (2010), "is financial sustainability and social cohesion, we need legislative progress aimed at the reform of the institutional and political governance of the NHS". The concept of accessibility on the other hand, points to the need to promote equity in the sense that equal needs ask for access to medical service of equal quality and competence (Oteo, 2010). As stated by authors such HanLon et al., (2011), some of these paradigms, heirs of a welfare state increasingly difficult to sustain from a financial point of view, add first-order questions to the set of overwhelming circumstances that challenge the sustainability of the health system, especially those related to finding the way to allow the system to perform as effectively as possible. The idea, as these authors suggest, is to find a new model to navigate through the phase transition in which we find ourselves, through a greater integration of different health policies and Issues related to cultural change. The proposal of a mix of equity-oriented policies from all levels of government, not only from health policies, but also from the environmental, transport, labour market and education policies is a matter that is still pending development (MUNTANER et al., 2011).

\section{The Spanish health system}

In Spain, the national health system was instituted in the late '70s of XX century, reflecting the aspiration of new times in the country to move towards a welfare state, with equity, redistribution and transfer of powers to Autonomous Communities (WHO, 2010). The decentralization process in matters of public health that culminated in the year 2002, meant de facto, the creation of seventeen different health systems and the lack of a system of health financing as the allocation of funds was integrated in each autonomic budget (Repullo and Freire. 2008). On the other hand, according to a WHO report (2010), health spending in Spain has followed the upward trend present in other neighbouring countries. The report, which addresses health systems in transition, notes that in the case of Spain the percentage of GDP spent on health was $8.5 \%$ in 2007, still below the European average. It also notes that $71 \%$ of spending was financed with public funds through taxes, $22.4 \%$ directly by citizens, and the remaining $5.5 \%$ by private insurance. Subsequently, the Royal Decree 16 of 2012, issued on April 20 (RD, 2012) introduced urgent measures to ensure the sustainability of the national health system and to improve the quality and safety of its performance by changing, among other measures, the percentages of co-payment pharmaceutical expenses. Public health expenditure is broken down as follows: $54 \%$ in specialty care, $16 \%$ in primary care, $19.8 \%$ in pharmaceutical expenditure, and $1.4 \%$ in public health and prevention (WHO, 2010). In relation to the percentage of GDP devoted to spending 
on health, different factors and variables that can affect this figure have been discussed widely as in the case of income, says Urban (2006), since the income elasticity of expenditure health is above the unit, $1.31 \%$.

According to the OECD in 2006, the proportion of public health expenditure on total health spending in Spain fell by $-7.8 \%$ in the period 1990-2004. According to the same source, per capita health expenditure in Spain is still below the OECD average in terms of purchasing power parity.

In the early '80s it was argued that there was not really a budgetary tradition for the health sector in Spain (De Miguel, 1980), and that the system had always foreseen expenses well over the budgeted. Thirty years later, this view persists even though the private sector has been covering the lack of investment in health and mitigating the gap in accessibility whose more egregious manifestation has been and still is the waiting lists articulated as a management mechanism for limited resource to a growing demand CIREM (2006).

Increasingly, more voices advice in the same direction, while it is in public health where this new concern takes a blatant shape: "... the new ghost who travels the world is that of sustainability" (Repullo and Segura, 2006, p. 479). On one hand, the authors note, the necessity of an effective management of financial resources in relation to external agents, the expansionist drive of the pharmaceutical industry, and the advances in electromedicine driving the spending growth. A solid foundation in decision-making would be required when introducing innovations into the system, particularly from a cost-benefit perspective. On the other hand, from the internal aspect a new awareness of the role of public health workers including the social dimension is sought -the need to "disrobe out of the white coat" to render the necessary support to patients and their close ones to achieves enough patient empowerment patient to encourage joint Responsibility of the patient with the disease- especially in chronic diseases that in ten years from now will account for $60 \%$ of every disease, currently representing $70 \%$ of total health expenditure (McKInSEY and FEDEA, 2009). The attention received by the citizen from the time of entry into the health care system through primary care should go beyond medical assistance by means of actions aimed both at the family and community (Repullo and Segura, 2006).

In a decentralized health system as it is the Spanish, a regional approach in the study from a autonomic perspective seems appropriate, and contributes to the analysis of first- order variables such as heterogeneity, efficiency, equity and the funding issues as a whole. In this direction Oñorbe Segura (2010) cites BuAdes et al., (2009), "leads us to consider the role of the state and of the autonomous territories, as the relationships between the various relevant authorities (not forgetting the local authorities) are in themselves an important variable? ¿Dependent, independent or perhaps, a confounding factor? As key points the authors point out the need for a centralized leadership with a focus on mutually beneficial cooperation between authorities, based on a thorough analysis of the current situation. However, to our knowledge ideological inclinations could act as barrier an obstacle to dialogue and a common vision needed to build such a sustainable system, since perhaps political actors are more interested in partisan benefits than in the final target of public health. Governance and transparency appear in this context as opportunities for improvement (ISRAR and ISLAM, 2006) in administrative routines and procedures that could be protecting partitocracy (MeneU and ORTún, 2011). As mentioned by Arredondo and Orozco (2008), health governance is related to the way in which civil society and political actors inside the health system distribute and

consume health, taking into account the demand and the need for health services; in this context, successful strategies for health policies are considered by these authors as the result of a broad 
consensus between every political agent. In terms of sustainability, it is associated with the concept of stakeholders' management (FreEMAn, 1984).

In this situation, tools such as Agenda 21 as local action plans that take into account the social, economic and environmental element, are useful for the cooperation needed to lead an improved quality of life for people (BARRUTIA and EcheVARRía 2011). The sixth chapter of Agenda 21, entitled "Protection and Promotion of Human Health", stated as objectives "to meet the basic health needs of rural peri-urban and urban populations; to provide the necessary specialized environmental health services; and to coordinate the involvement of citizens, the health sector, the health-related sectors and relevant nonhealth sectors (business, social, educational and religious institutions) in solutions to health problems. As a matter of priority, health service coverage should be achieved for population groups in greatest need, particularly those living in rural areas." (Agenda 21). The approach to these objectives should include a perspective of health for everyone from a holistic vision; cooperative, focused on people and on the environment, reached by consensus with every stakeholder, with equity and social justice, all encased in a sustainable format (Dooris, 2001). Also, it seems essential the involvement of local and regional governments in a dialogue with citizens, healthcare organizations when applicable, and private companies to adopt this agenda in every different level of implementation (Feichtinger and Pregernig, 2005). Health plans as a way in which the health goals of the autonomous territories can be captured would on the other hand, an appropriate instrument to reflect such goals and the pertinent monitoring indicators. In Spain, as noted by Llamas Sanchez et al., (2011) the effort of implementing Agenda 21 does not come from the central government but from the Autonomous Communities with the involvement of local authorities. The concept of empowerment, the quest for commitment and the creation of a culture around Agenda 21 are relevant factors for its implementation. Citizen participation is essential in the process (Martínez and RoseberRy, 2010). However, as these authors note, in Spain the implementation of local programs related to the objectives of Agenda 21 has had little impact, citing a study by Font and SubiRATS (2000). Still more in a healthcare environment in which the responsibility of individuals as healthy citizens first, and as patients from different diseases someday, asks for the knowledge and the awareness necessary to improve their own circumstances of life, thereby contributing to the financial sustainability of the public health system.

\section{Methods}

The aim of this paper is to analyze the vision that public managers of the Spanish health system have on a sustainable health system, comparing this view with a concept of sustainability of the health system understood from a broad perspective, i.e. considering economic and financial issues and including social and environmental dimensions. The study of models of sustainability requires many tools and skills combined for analyzing social phenomena (Kates et al., 2001). In this paper, a survey has been carried out from a database of eighty-five senior officials in the health administration of the Autonomous Communities (CCAA). For the collection of such the most commonly used methods has been telephone surveys and personal interviews as noted by Scheaffer et al., (1987). In turn, an in-depth, semi-structured interview was conducted with the Autonomic Minister for Health of an Autonomous Community. The interview as a research method is used to achieve more depth on global and theoretical aspects of the specialized discourse (both ideological and professional) where the latter find its support (BAEZ, 2007).

The survey was conducted in May 2010, during a period of 20 days, between the $3^{\text {rd }}$ and $23^{\text {rd }}$ of 
the same month, and received thirty-four answers from a total of ninety surveys sent.

\section{Results}

\section{Results of the survey}

An indeterminated number of the eighty-eight recipients did not receive the survey for technical reasons while 25 answers were obtained from the remaining people, resultant in a response average of $28.4 \%$.

From the results we can conclude that establishing a ranking for importance in the following order is often useful: economic, social and environmental factors. This latter dimension alone was not chosen by any of the respondents as the most important while the economic dimension as the only option was chosen by $42 \%$ of cases, compared with $31 \%$ for social elements. However, the fact that $27 \%$ stated an equal importance in all three dimensions denotes a clear and prevalent vision of the true essence of the concept of sustainability in organizations. (Figure 1)

A widespread perception throughout the study is that health is not sustainable at least in the present circumstances; in fact there are two clear priorities in order to improve the situation. For one, you need a more efficient management and cost control, this option appears in $56 \%$ of respondents as the most necessary, and second, with a frequency of $28 \%$, to maintain the current performance model a greater budget for health was often cited. Both aspects relate to two of the suggestions considered by some authors, the external sustainability refers to the relationship with suppliers and cost control, and internal sustainability on the one hand, relates to management, and on the other hand, to budget allocation for health, which should be consistent with the generation of expectations in the population and with the supply in the service portfolio (Repullo and Segura, 2006). (Figure 2)

The degree of agreement on whether the legal framework is relevant for the sustainability of the health system, the results show that a majority disagrees which comes to show that managers perceive a mismatch between the legal framework and the actual needs of the system. (Figure 3)

Figure 1: What aspects are relevant from your point of view to achieve a Sustainable health system?

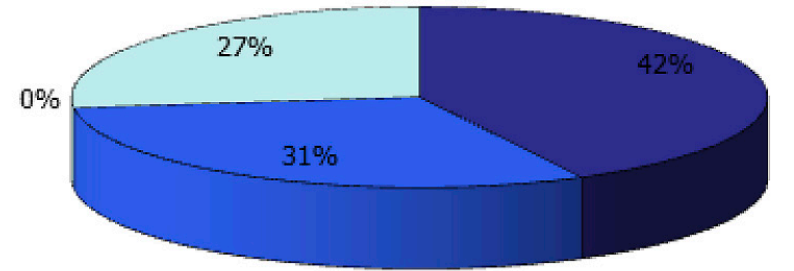

Economic: 42\%; Social: 31\%; Ambiental: 0\%; All of above: 27\%

Figure 2: Which of these statements do you most agree with?

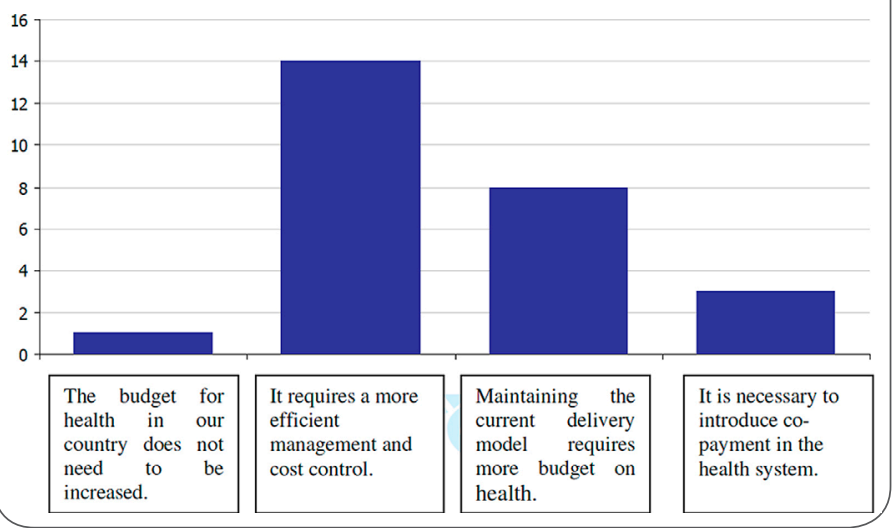

Figure 3: Indicate how much you agree/disagree with the following statement: The Sustainable Economy Act is important for the sustainability of the health system. 1 strongly disagrees and 5 strongly agree.

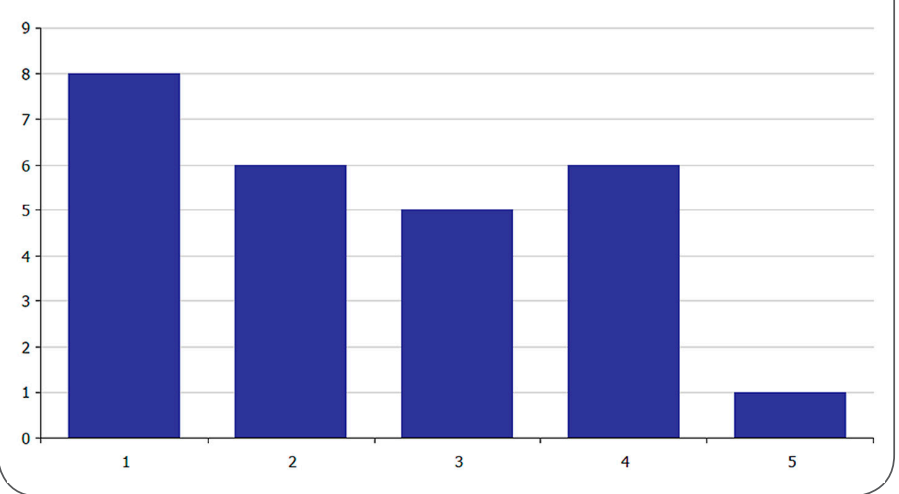


Figure 4: Do you think that social aspects are as important as economic?. The social aspects are equally important to the economic sustainability of the health system. $1=$ | strongly disagree to $5=1$ strongly agree.

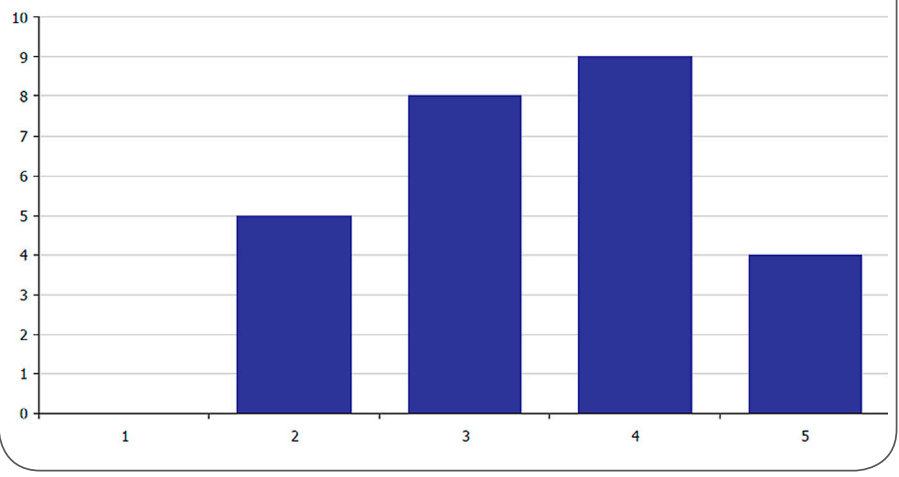

The relevance between the different dimensions of sustainability has been analyzed two-dimensionally, for example, it was asked for the consequence of social versus economic factor by trying to place them on the same level of importance. The chart shows that while none of the respondents strongly disagreed with the assertion that social aspects are as important as economic, there was not a clear answer that explicitly acknowledged that both dimensions are equally important for the sustainability of the health system. The shape of the histogram, if we draw an imaginary normal curve from response one through five, describes a figure slightly skewed to the right, indicating that the perception that both aspects should be equally important is high. (Figure 4)

When performing the same exercise with the environmental and economic dimensions there is a clear contrast with the analysis of social and economic variables. The environmental dimension becomes irrelevant in this comparison of pairs in what seems to set a sequence in order of importance that would go in the following sense: first the budget or money, then people and ultimately, the environment. It is unclear whether this perception of different levels of importance of the three dimen-
Figure 5: Do you think that environmental aspects are as important as economic?. The environmental aspects are equally important to the economic and social sustainability of the health system. $1=1$ strongly disagree to $5=$ I strongly agree.

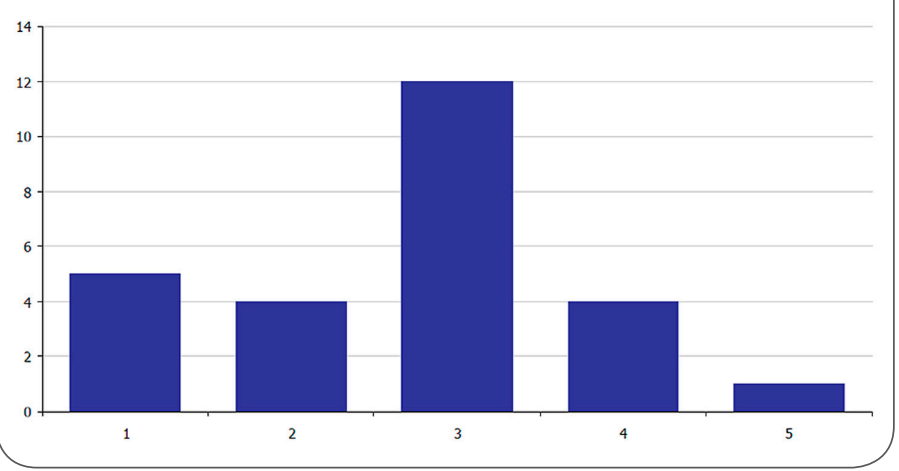

sions of sustainability, is due in part to the context or situation of crisis or a natural, intrinsic sequence that possibly derives more from the logic of rational thought than from a rigorous analysis and understanding of the concept of sustainable development applied to healthcare systems. (Figure 5)

The order of importance placed to these different dimensions, particularly the economic factor is well exposed in the following question, which directly seeks from the respondent a clear positioning on the economic factor. While an affirmative bias is appreciable, it is remarkable the fact that there is who denies it or plays it down when the question is not brought in comparative terms and it refers specifically to one dimension. (Figure 6)

Regarding the range of the objectives of Agenda 21 the result of the survey shows that in $52 \%$ of the answers it was estimated that these objectives were not being met, or at least, that the current orientation favours such meeting such goals. It is significant that $40 \%$ of respondents does not know, which may be due to I). - The respondent has not done the necessary checks and lacks adequate information, or II.) - There is a certain level of ignorance regarding the content of the objectives of Agenda 21 by the administrators and managers of health 
administrations; though it may be a combination of both reasons. (Figure 7)

The implementation of these objectives should be accomplished through the development of Local Agenda 21 depending on the needs to meet the program and perhaps this fact, could have generated timing and relevance imbalances in different countries and regions. Besides, the development of such agendas requires an effective involvement of policy makers that should match the agenda for planned legislative objectives in each parliamentary or mandate term. The necessary political differentiation may not help the inclusion of similar projects in the agendas of parties that may be very apart in their ideological positions.

Finally there have been two specific but generic questions that citizens may be asking themselves given the current circumstances; essential from the point of view of the perception that managers and politicians have about the sustainability of the health system and the degree of trust in it. From the respondents, 56\% believe that the Spanish health care system is not sustainable, compared to $40 \%$ that thing it is, and $4 \%$ that admittedly do not know. This result alone begs to take action from the diverse, possible measures needed to reverse this trend; it is clear that the weight of the "payable" in short-term conditions the perception of non-sustainability of the health system, but it would be a strategic mistake not to make an overall design, letting the budgetary cutbacks as the only ideal solution under the thought that just with this "emergency cure" the system will be sustainable. (Figure 8 )

The inclusion of agents or interest groups is essential in such an important aspect both for citizens and for society as a whole such as the sustainability of the health system. However, the will, the chances or the degree of trust in the utility do not reflect positively in the survey. It should be weighed that the question was posed regarding whether or not the Administration consider citizens in the design of
Figure 6: Are the economics aspects the most important for the sustainability of the health system?. The economic aspects are the most important in the sustainability of the health system. 1 = I strongly disagree to $5=$ I strongly agree.

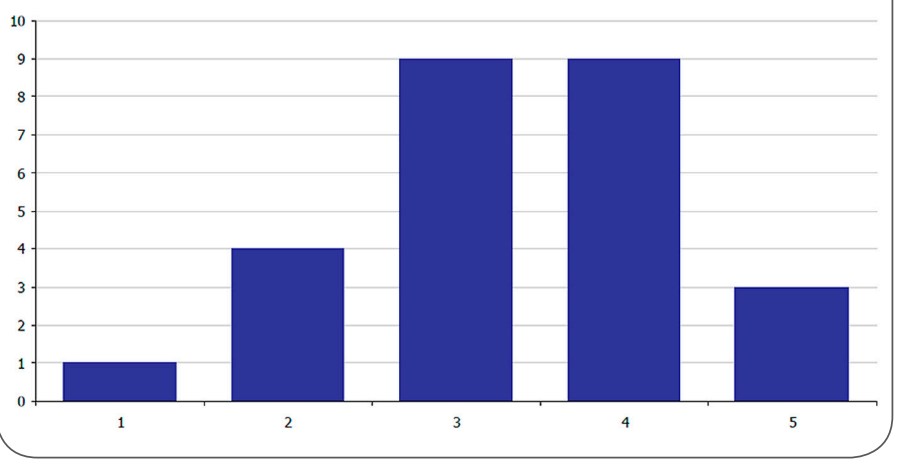

Figure 7: Do you think that the objectives of Agenda 21 are implemented in the health plans of every CCAA?

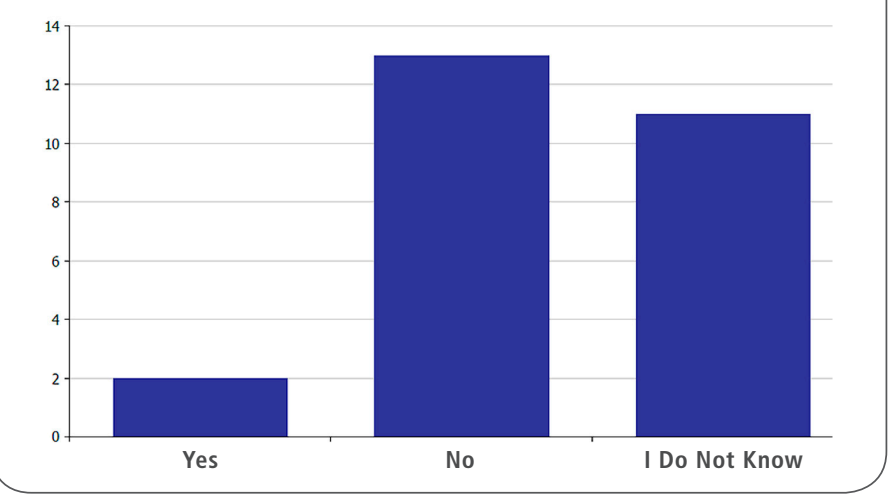

Figure 8: Do you think that the objectives of Agenda 21 are implemented in the health plans of every CCAA?

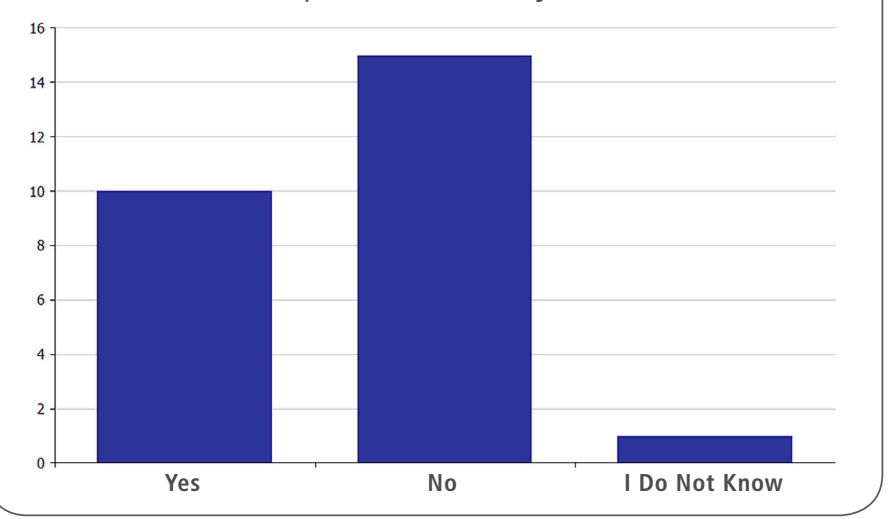




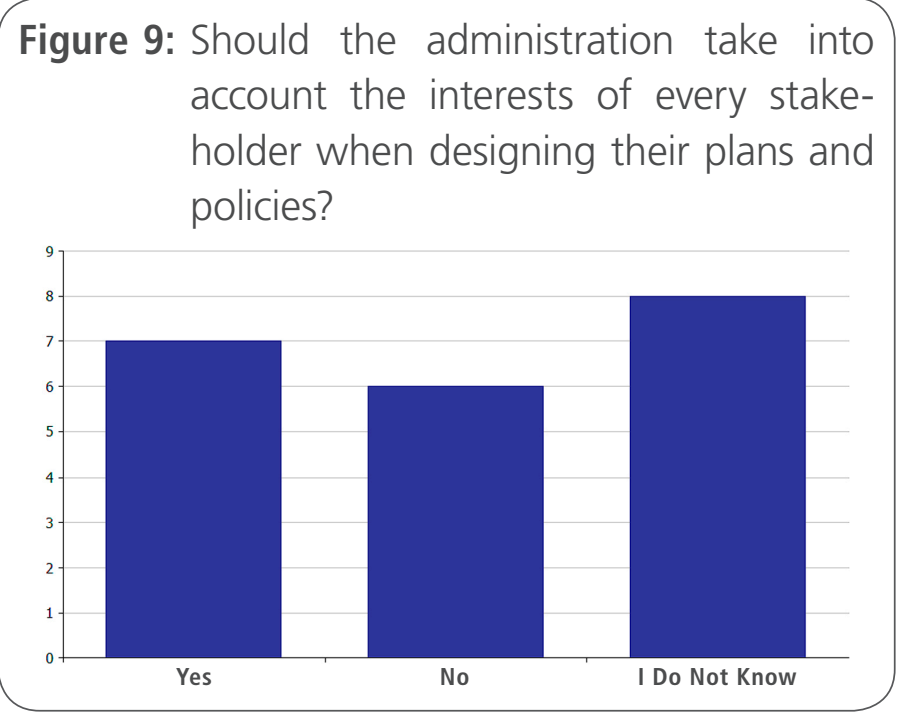

plans, leaving out any possible reasons that might have prevented it. (Figure 9)

Comments on the semi-structured interview conducted with the Autonomic Minister for Health of an Autonomous Community.

The sustainability of the health system has priorities such as finance and human resources management. Regarding the first question, the general opinion among the Directors of Health is that funding should be finalist, i.e., the initial budgetary allocation for health from the State to the Autonomous Community cannot be subsequently transferred to address other spending needs different than the allotted. Moreover, a route proposed for addressing human resources would be a common policy throughout the country under the Ministry of Health. Other issues that remain outstanding for future Council meetings, but no less important, are the evaluation of the portfolio of services that is to grow to be more restrictive in the opinion of the Director, and the usefulness of the Cohesion Fund.

Public health care must be universal and free, technology-based and in the prevention of diseases and, above all, it is essential to uphold the principle of equity. However, as of today the premises of the Spanish health care system make it unsustainable, it is essential to control both the spending growth and the demand. People live longer and increasingly nowadays; meeting patients in the office who are one hundred year-old is not an anecdote. This fact means that soon for many people, inactive live will extend for as long as active life. The proportion of the budget of the CCAA devoted to public health is currently $30 \%$ but studies foresee that in ten years under the current conditions, this percentage will increase $70 \%$ according to the Autonomic Minister, making it financially unsustainable, as chronic patients should remain on the radar to adequately addressed their health and to prevent complications and higher costs in the medium term. Furthermore, the Dependency Act plays a key role in health and social care: We must take into consideration that many of these patients are not self-reliant and are unable to live without the support of a third person. To aspire to meet this demand will further increase budgets and it will require specific planning.

The consequence of environmental factors is not lost; many of the diseases contracted by patients are related with the environment in which citizens live each day and their living habits; other indicators such as the increased incidence of allergies lead us to believe that something must be changed in the environment that it is not provided. Technology and innovation are critical to solving many of these problems. The countries that now invest in innovation will the first to overcome the crisis, as they will be prepared and not dependent on others to grow back again.

Regarding the possibility of introducing other measures such as co-payment, the Minister believes that Spain already has instituted such a tool, active citizens are charged $40 \%$ for pharmaceutical products, an in spite of this, a rearrangement of the copayment is essential to make it more fair. The criteria of proportionality in the contributory efforts provide the ability to manage equity efficiently; managers know that it is a complex tool, and that the health system has room for improvement. During the interview, experiences in other countries arose, and measures like the health ticket meant to 
act as moderating factor that rationalizes demand were mentioned, understanding that although its many detractors its rationale should be pondered and then, acknowledged as it is meant to prevent the compromise of the accessibility and equity of the health system. The most prominent lines in the health policy forums are: Finance, pharmacy, human resources and service portfolio. The orientation tends towards an agreement that goes beyond mere theoretical discussion, and being regulated by law, will not left open any unresolved issues. It is important also, that that covenant allows for the development of specific national plans for issues such as dependency, diabetes, and other chronic diseases that are held as priorities. Spain is one of the EU countries that allot a lesser budget in terms of GDP to public health, opening thus, a space to private initiative whose relative weight is increasing.

\section{Conclusions}

The sustainability of the health care system is a matter of grave concern to the political class of our country regardless of ideological orientation. However a good measure of the action taken revolves around the economics of the system, an element that is perceived as key for its sustainability. We understand that this approach to the economic factor has a strong bias due to the economic crisis that suffers the country in particular, and that is of widespread influence in the West, since the second half of the first decade of this century. However, the economic dimension has a particular inclination towards shortterm management, towards measures for urgent cut downs, often adopted without any effort to reach a consensus with stakeholders (government by fiat trend). Public participation is blatantly unlisted as one of the relevant considerations for managers of the public health system, either because they do not trust the judgment of citizens in matters of public affairs, or because the se- paration of the political class from the rest of individuals seems to grows in times of crisis. This line of urgent action is urgent driven by necessity sets itself well apart from any model for sustainable development, although this concern is known for most of the respondents who show that the social and environmental dimensions are equally relevant to the sustainability of the system. It is notable the emphasis placed on the weight of budget management, while the importance of the Triple Bottom Line does not appear adequately reflected.

The communication tool that seems most appropriate and has the added advantage to act as a strategic support for governmental action policies regarding health care is the Health Plan, a document that the regions have been publishing in an irregular fashion, setting out the policies and actions to be carried out during the following period, which is variable in each case. It seems to us to be desirable to use the Health Plan as a means to emphasize health policies that would cover the various aspects relating to Sustainable development criteria, the economic side, especially on the social participation and environmental citizen. The construction of monitoring indicators in every aspect could facilitate the monitoring criteria of continuous improvement and health outcomes of the population. Moreover, the extension to specific plans concerning diseases that affect a large number of the population, as is the case for chronic disease, could benefit from a more holistic approach to those proceedings.

The political discourse is more concerned with ideological aspects, variables that are readily transferable to the population as messages that are profitable offering a return in the form of votes in the polls: accessibility, universality, gratuity etc. These messages are often embroiled in a tide of interpretations and variations difficult to sort scientifically. The research on health plans could shed light by comparing the heterogeneity of the different health 
authorities in Spain, and by deduction, finding the possible patterns that may emerge when dealing with health from a sustainability perspective.

\section{References}

- Arredondo, A. and Orozco, E. 2007. Equity, governance and financing after health care reform: lessons from Mexico. Int J Health Plann Manage 23: 37-49.

- Baez, J. 2007. The interview. In: ESIC, ed. 2007. Qualitative Research. Madrid.

- Barrutia, J.M. and Echevarría, C. 2011. Explaining and measuring the embrace of Local Agenda 21s by Local Governments. Environment and Planning A 43: 451-469.

- Baxter, B. (2010). For families, actions speak louder than words. Eval Program Plann 33: 39-40.

- Benedict, A. and Oñorbe, M. 2010. Changes in public health: the role of the state and autonomy. SESPAS Report 2010. Gac Sanit 24: 19-22.

- Brundtland, G. 2002. Health and sustainable development. ICE Desarrollo Sostenible 800: 173-179.

- Buades, M., Plasencia, A. and Head, E. (2009). The public health reform, Gac Sanit 23: 462-464

- CIREM. 2006. A Sustainable Health System. Circle Publishing Company, Madrid. United Nations Conference. 1992. Environment and development. Available at: http://www. un.org/es/ [Accessed on June 9th, 2010]

- De Miguel, J. 1980. Seven erroneous theses of the Spanish health policy, and a critical sociological alternative. Reis 9/80: 53-80

- Dohuk, 2004. Healthy Making Choosing Easier. NHS, UK. Available at: http://www.nhs.uk/aboutNHSChoices/ professionals/lifecheckers/aboutus/Pages/background.aspx [Accessed on September 25th, 2012 ]

- Dooris, M. 2001. The health promoting university: a critical exploration of theory and practice. Health Educ 101: 51-60

- Ebi, K. and Burton, I. 2008. Identifying practical adaptation options, an approach to address climate change-related health risks. Environ Sci Policy 11: 359-369.

- El Ansari, W. and Stibbe, A. 2009. Public health and the environment: what Literacy skills for sustainability - and why? Sustainability 1: 425-40.

- Feichtinger, J. and Pregernig, M. 2005. Imagined citizens and participation: local agenda 21in two communities in Sweden and Austria. Local environment 10: 229-42.

- Fiona, A., Thorpe, A. and Rutter, J. 2006. Sustainable development and public health: Anational perspective. Public Health 120: 1102-1105.

- Freeman, R.E. 1984. Strategic Management: A Stakeholder Approach. Pitman Press, Boston.

- Gervás, J. and Meneu, R. 2010. The public health crisis in a developed society. Successes and limitations in Spain. SESPAS Report. Gac Sanit 24: 33-36.

- Guite, H.F., Clark, C. and Ackrill, G. 2006. The impact of the physical and urban environment on mental well-being. Public Health 120: 1117-1126.
- Hanlon, P., Carlisle, S., Hannah, M., Lyon, A. and Reilly, D. 2011. Learning our way intothe future public health, a proposition. J Public health 33: 335-342.

- Haines, A., Kovats, R.S., Campbell-Lendrum, D. and Corvalan, C. 2006. Climate change and human health: Impacts, vulnerability and public health. Public Health 120: 585-596.

- Heinonen-Tanski, H., Surendra, K. and Karinen, P. 2010. Sustainable sanitation. A cost effective tool to improve plant yields and the environment. Sustainability 2: 341- 353.

- Israr, S.M. and Islam, A. 2006. Good governance and sustainability: a case study from Pakistan. Int J Health Plann Manage 21: 313-325

- Jameton, A. and McGuire, C. 2002. Toward sustainable healthcare services: principles, challenges, and a process. International Journal of Sustainability in Higher Education 3: 113-127.

- Jochelson, K. (2006). Nanny or steward? The role of government in public Health. Public Health, 120, pp. 1149-1155.

- Kates, R. W., W. C. Clark, R. Corell, J. M. Hall, C. C. Jaeger, I. Lowe, J. J. McCarthy, H. J. Schellnhuber, B. Bolin, N. M. Dickson, S. Faucheux, G. C. Gallopin, A. Gruebler, B. Huntley, J. Jaeger, N. S. Jodha, R. E. Kasperson, A. Mabogunje, P. Matson, H. Mooney, B. Moore, III, T. O'Riordan and U. Svedin 2001. Sustainability Science. Science 292: 641-42.

- Kickbusch, I. 2009. Policy Innovation for Health. In:Innovation for Health. Geneva. Springer.

- Komiyama, H. and Takeuchi, K. 2006. Sustainability science: building a new discipline. Sustainabiliy Science 1: 1-6.

- Flame-Sánchez, R., Muñoz-Fernández, A. and Maraver-rate, G. 2011. The Local Agenda 21 in Andalusia, Spain: a model for sustainable innovation. African Journal of Business Management 5: 12653-12663.

- Martin, J. and López del Amo, M.P. 2011. The sustainability of the National Health System in Spain. Department of Applied Economics, Faculty of Economics and Business. Campus Universitario de Cartuja, s/n. Artigo, article, No 2773. Granada.

- Martínez, M. and Roseberry, S. 2010. Participación ciudadana en las Agendas 21: cuestiones críticas de la gobernanza urbana. Electronic Journal of Geography and Social Sciences 15. Available at: http://www.ub.edu/geocrit/sn/sn-355.htm

- McKinsey and Fedea 2009. Impulsar un cambio posible en el sistema sanitario. Fundación de Estudios de Economía Aplicada. Foundation Applied Economics. Studies. Available at: http://www.cambioposible.es/documentos/sanidad_cambio_ posible.pdf [Retrieved on February 25 ${ }^{\text {th }}, 2013$ ]

- Meneu, R. and Ortún, V. 2001. Transparency and good governance in health. Also out of the crisis. Gac Sanit 25: 333338.

- Moser, P. 2001. Glorification, disillusionment or the way into the future? The significance of Local Agenda 21 processes for the needs of the local sustainability. Local Environment 6: 453-67.

- Muntaner, C., Benach, J., Tarafa, G. and Chung, H. 2011. The wellfare state and global health, Latin America, the Arab world and the politics of social class. Gac Sanit 25: 445-447.

- Oteo, L. A. 2010. La sostenibilidad del Sistema Nacional de Salud: los profesionales sanitarios y la ciudadanía. Revista Administración Sanitaria 8: 5-32. 
- Pecurul, M. and Peray, J. L. 2010. Trabajando hacia una salud pública sostenible mediante la interrelación de lo ambiental y lo social. Informe SESPAS. Gac Sanit 24: 74-77.

- Potvin, L., Gendron, S., Bilodeau, A. and Chabot, P. 2005. Integrating social theory into public health practice. Am J Public Health 95: 591-595.

- Potvin, L., Mantoura, P. and Ridde, V. 2010. Evaluating equity in health promotion. In: McQueen, D.V. and Catherine M. Jones, C. M., Global Perspectives on Health Promotion Effectiveness. Springer, New York.

- Rae, M. 2006. Health Inequalities - A sustainable development issue. Public Health 120:1106-1109.

- Royal Decree-Law 4/2010, of March 26th, on pharmaceutical expenditure under the National Health System. Disposition 5030. BOE, No 75, March 27th , 2010. Section I, p. 28989.

- Repullo, J. and Freire J. 2008. Governance of the NHS: improving the balance between the benefits and costs of decentralization. SESPAS Report. Gac Sanit 22: 118-25

- Repullo, J. and Segura. A. 2006. Salud Pública y Sostenibilidad de los sistemas públicos de salud. Revista Española de Salud Pública 80: 475-82.

- Repullo, J. 2009. Identification and modulation of systematically irrational behavior in medicine and public health. Revista Española de Salud Pública 83:43-57.

- Rio, 2011. World Conference on Social Determinants of Health. WHO, Rio de Janeiro, October 19 to 21, 2011. Available at:m http://www.who.int/sdhconference/declaration/Rio political declaration Spanish.Pdf [Accessed on September 19th , 2012]

- Schaeffer, R., Mendenhall, W. and Ott, L. 1987. Sampling Elements. Spanish Version of thework Elementary Survey Sampling. $3^{\text {rd }}$ ed. Mexico DF, Editorial Grupo Editorial Iberoamérica.

- Rae, M. 2006. Health Inequalities - A sustainable development issue. Public Health 120: 1106-1109.

- Royal Decree-Law 4/2010, of March 26th, on pharmaceutical expenditure under the National Health System. Disposition 5030. BOE, No 75, March 27th, 2010. Section I, p. 28989.

- Repullo, J. and Freire J. 2008. Governance of the NHS: improving the balance between the benefits and costs of decentralization. SESPAS Report. Gac Sanit 22: 118-25

- Repullo, J. and Segura. A. 2006. Salud Pública y Sostenibilidad de los sistemas públicos de salud. Revista Española de Salud Pública 80: 475-82

- Repullo, J. 2009. Identification and modulation of systematically irrational behavior in medicine and public health. Revista Española de Salud Pública 83:43-57.

- Rio, 2011. World Conference on Social Determinants of Health. WHO, Rio de Janeiro, October 19 to 21, 2011. Available at: http://www.who.int/sdhconference/declaration/Rio political declaration Spanish.pdf [Accessed on September 19th 2012]

- Schaeffer, R., Mendenhall, W. and Ott, L. 1987. Sampling Elements. Spanish Version of the work Elementary Survey Sampling. $3^{\text {rd }}$ ed. Mexico DF, Editorial Grupo Editorial Iberoamérica.
- Waddock, S.A. and Graves, S.B. 1997. The corporate social performance-financial performance link. Strategic Management Review 10: 758-769.

- Werbanch, A. 2009. Sustainable Strategies: A Manifesto for the Twenty-First Century Business. Urano, Barcelona.

- WHO. 2005. Bangkok Charter for Health Promotion in a Globalized World. Available at: http://www.who.int/ healthpromotion/conferences/6gchp/BCHP es.pdf [Accessed on September 15 $5^{\text {th }}, 2012$ ]

- WHO Regional Office for Europe, 2008. The Tallinn Charter: health systems for healthand wealth. WHO Regional Office for Europe, Copenhagen. Available at: http://www.euro.who.int/ document/E91438.pdf

- WHO, 2008. Ottawa Charter for Health Promotion. Available at: www.paho.org/english/hpp / ottawachartersp.pdf [Accessed on September $3^{\text {rd }}$, 2012]

- WHO 2009. Reducing health inequities through action on the social determinants of health. 62nd World Health Assembly. WHA62. 14, Agenda item 12.5, May 22nd, 2009. Available at: http://apps.who.int/gb/ebwha/pdf files/A62/A62 R14-sp.pdf. [Accessed on September 16 ${ }^{\text {th }}, 2012$ ]

- WHO Europe, 2010. European Observatory on Health System and Policies. Spain. [Accessed on May $7^{\text {th }}, 2012$ ]

\section{Comment on this article:}
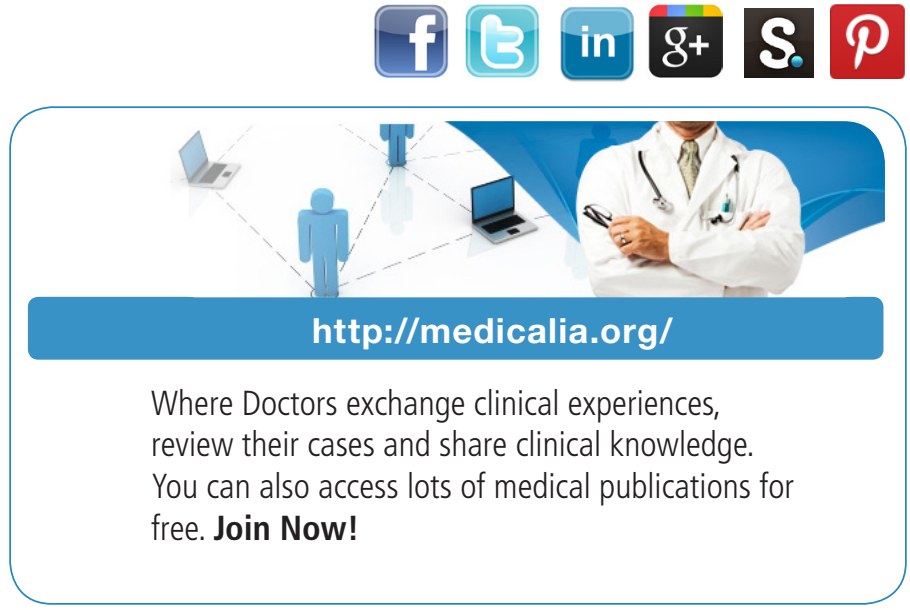

\section{Publish with iMedPub}

\section{http://www.imed.pub}

International Archives of Medicine is an open access journal publishing articles encompassing all aspects of medical science and clinical practice. IAM is considered a megajournal with independent sections on all areas of medicine. IAM is a really international journal with authors and board members from all around the world. The journal is widely indexed and classified Q1 in category Medicine. 